University of Nebraska - Lincoln

DigitalCommons@University of Nebraska - Lincoln

1996

\title{
Designing Supportive School Environments
}

\author{
J. Ron Nelson \\ University of Nebraska - Lincoln, rnelson8@unl.edu \\ Geoff Colvin \\ University of Oregon
}

Follow this and additional works at: https://digitalcommons.unl.edu/specedfacpub

Part of the Special Education and Teaching Commons

Nelson, J. Ron and Colvin, Geoff, "Designing Supportive School Environments" (1996). Special Education and Communication Disorders Faculty Publications. 41.

https://digitalcommons.unl.edu/specedfacpub/41

This Article is brought to you for free and open access by the Department of Special Education and Communication Disorders at DigitalCommons@University of Nebraska - Lincoln. It has been accepted for inclusion in Special Education and Communication Disorders Faculty Publications by an authorized administrator of DigitalCommons@University of Nebraska - Lincoln. 


\title{
Designing Supportive School Environments
}

\author{
J. Ron Nelson \\ Eastern Washington University \\ Geoff Colvin
}

University of Oregon

\begin{abstract}
SUMMARY. There is no question that all students, especially those with serious emotional disturbance, benefit from a predictable, consistent, well-organized, and safe school environment. The purpose of this paper is to describe and illustrate an effective approach that has had positive results in achieving such a school environment. Specifically, the paper describes how to achieve effective ecological arrangements and common area routines across the school environment. In addition, we present a case study with preliminary results. [Article copies available from The Haworth Document Delivery Service: 1-800-342-9678.]
\end{abstract}

What role can the school play in preventing serious emotional disturbance (SED)? We can identify children who have extreme behavioral

Address correspondence to: J. Ron Nelson, Department of Applied Psychology, Eastern Washington University, Cheney, WA 99004.

Preparation of this manuscript was supported in part by grants (\#H237D20011 and \#H029K10092) from the U.S. Department of Education, Office of 'Special Education Programs. Opinions expressed do not necessarily reflect the position of the U.S. Department of Education, and no endorsement should be inferred.

[Haworth co-indexing entry note]: "Designing Supportive School Environments." Nelson, J. Ron, and Geoff Colvin. Co-published simultaneously in Special Services in the Schools (The Haworth Press, Inc.) Vol. 11, No. 1/2, 1996, pp. 169-186; and: Emerging School-Based Approaches for Children with Emotional and Behavioral Problems: Research and Practice in Service Integration (ed: Robert J. Illback, and C. Michael Nelson) The Haworth Press, Inc., 1996, pp. 169-186. Single or multiple copies of this article are available from The Haworth Document Delivery Service [1-800-342-9678, 9:00 a.m. - 5:00 p.m. (EST)].

(c) 1996 by The Haworth Press, Inc. All rights reserved. 
problems early in their educational careers, but if no attempts are made to support their coping and resiliency, they are likely to have poor educational and career outcomes (Edgar \& Levine, 1987; Kauffman, Cullinan, \& Epstein, 1987; Neel, Meadow, Levine, \& Edgar, 1988). The time has come to make our schools supportive environments that promote children's social development. There is no question what types of environments promote the social development of children. The worst outcomes are achieved in environments that are either harsh and punitive in nature, or inconsistent in their expectations of child behavior and its consequences. The best outcomes are achieved when the environment is predictable, consistent, well-organized, and safe.

Unfortunately, across America, the predictable, consistent, well-organized, and safe school environment of earlier decades is past (Morrison, Furlong, \& Morrison, 1994). In all too many cases, schools have become disorderly, unsafe, and disruptive to the teaching and learning process. This is unfortunate because developing a predictable, consistent, well-organized, and safe school environment is not only a low-cost, long-term, and highly effective way for schools to manage their common disciplinary and behavior problems, but is also fundamental to the development of children's psychological competencies, learning functions, and motivations (Gilbert, 1993). Such a school environment is both preventative and restorative in nature. A predictable, consistent, well-organized, and safe school environment is preventative, in that it does not provide the context in which behavioral problems arise or become more entrenched. Such a school environment also is restorative in that it provides the structure necessary to remediate problem behavior.

Two primary interrelated elements must be considered to achieve a predictable, consistent, well-organized, and safe school environment: (a) ecological arrangements; and (b) common area routines. The focus of the first element is physical arrangements and the scheduling and use of space. The focus of the second element is the common area routines. Entering, exiting, and feeding hundreds of students, for example, are extremely complex activities requiring a great deal of planning. Unfortunately, we have found that schools typically have ineffective ecological arrangements and common area routines. The institutionalized ecological arrangements and common area routines used by schools have been derived historically with little thought given to their effectiveness. Poorly designed ecological arrangements and common area routines can result in high levels of disciplinary and behavior problems.

The purpose of this paper is to describe and illustrate an approach that has had positive results in achieving a predictable, consistent, well-orga- 
nized, and safe school environment which promotes the social development of children. In addition, we present a case study with preliminary results. This approach is based on work conducted in a number of elementary schools serving high numbers of students with SED and those who are at risk for developing SED. The schools are all located in low socioeconomic neighborhoods (over $70 \%$ of the students qualify for free or reduced lunches).

The development and implementation of effective ecological arrangements and common area routines is a relatively time-consuming process. However, taking the time to develop such arrangements and routines within the school not only will result in a predictable, consistent, well-organized, and safe school environment conducive to learning, but also will enhance staff morale, reduce stress and burnout, and improve community relationships. We have identified five steps for developing and implementing effective ecological arrangements and common area routines: (a) establishing a committee to guide the development, implementation, and maintenance of the ecological arrangements and common area routines; (b) conducting a needs assessment of the ecological arrangements and common area routines; (c) revising the ecological arrangements; (d) establishing common area routines including responses to problem behavior; and (e) implementing the revised ecological arrangements and common area routines.

\section{ESTABLISHING A COMMITTEE}

The first step is to establish a committee to direct the development, implementation, and maintenance of the ecological arrangements and common area routines. Although the committee will direct and guide the process, it needs to be a joint venture with staff at all levels working together. Achieving consensus on the ecological arrangements and common area routines is essential to insure their implementation and maintenance.

The following factors should be considered when forming a committee. First, the composition of the team should be considered. Efficient teams generally are comprised of eight members (or less) who are representative of the entire staff. Broad representation is necessary to help achieve consensus among the school staff, and because each staff member will bring important information necessary for the development of effective ecological arrangements and common area routines. For example, it is difficult for teachers to understand fully all of the factors associated with the school lunch program without input from a staff member who is involved intimate- 
ly with that program. Other factors to consider when establishing a committee to develop effective ecological arrangements and common area routines include the length of term for team members and how team members will be selected. Because the ecological arrangements and common area routines are continually refined, a 2- to 3-year term is recommended with a proportion of the team members rotating off each year to insure continuity from year to year. There are a number of options for selecting team members. The particular process used for selecting team members should match standard practices for establishing other building teams. Some options for selecting members of the committee include: (a) administrative appointments; (b) call for volunteers; (c) staff nominations; or (d) election of team members.

The overall responsibility of the committee is to direct the development, implementation, and maintenance of ecological arrangements and common area routines. The responsibilities and general activities of the committee include: (a) attend all planning meetings; (b) identify current ecological arrangements and common area routines; (c) evaluate effectiveness of current ecological arrangements and common area routines; (d) revise/establish ecological arrangements and common area routines; (e) field-test revised or new ecological arrangements and common area routines that are being considered for implementation; (f) actively communicate with staff members regarding the activities of the committee; and ( $\mathrm{g}$ ) conduct staff meetings to ensure and evaluate the implementation and maintenance of ecological arrangements and common area routines. In addition, it is important for the committee members to be persistent. Effecting school change is extremely intense and will result in many heated exchanges. Committee members must push through these exchanges in a positive manner.

\section{CONDUCTING A NEEDS ASSESSMENT FOR THE COMMON AREAS}

A needs assessment is used to assess current ecological arrangements and common area routines. The needs assessment not only will provide school staff with a more accurate picture of current practices, but also will insure a variety of perspectives regarding them. The most accurate picture of what is happening with current ecological arrangements and common area routines can be obtained by: (a) collecting and analyzing data from multiple sources; and (b) involving all relevant parties such as students, parents, teachers, and support staff.

Methods for collecting the above information include surveys, interviews, observations, and reviews of records. Regardless of the method of 
data collection, the staff needs to understand how their responses will be treated, including the level of confidentiality. The following examples highlight possible approaches to collecting information to assess current ecological arrangements and common area routines:

1. Survey instruments. Surveys/questionnaires can be used to assess current practices and to establish development priorities. These may be open-ended or structured instruments.

2. Interviews. Individuals can be invited to participate in individual or group interviews to discuss current practices and their suggestions as well as to clarify or expand on responses to a survey.

3. Observations. Areas of the school can be observed by members of the committee. Observation data provide information about what is working well, in addition to identifying practices that need improvement.

4. Reviews of records. Archival school data can be reviewed to provide information on how well current practices are working, and the need for revising the record keeping system.

Figure 1 presents a checklist for determining the adequacy of the existing ecological arrangements, and Figure 2 presents a checklist for determining the adequacy of the common area routines.

\section{REVISING ECOLOGICAL ARRANGEMENTS}

Numerous opportunities for ecological arrangements will contribute to the productive management of the common areas of the school. Although the effective design and use of the constructed environment can reduce the incidence of problem behavior in the school, there is a tendency to overlook obvious ecological solutions to problems. Based on the results of the needs assessment, modifications may need to be made to the ecological arrangements in the common areas of the school: (a) eliminating or adjusting unsafe physical arrangements; and (b) improving the scheduling and use of space.

\section{Eliminating or Adjusting Unsafe Physical Arrangements}

Eliminating or adjusting unsafe physical arrangements involves actual structural changes and adjustments in the use of the space. Changes such as removing foliage, using barricades, or changing the designated use of an area (e.g., relocating gathering locations to areas with high levels of 
FIGURE 1. Checklist for Determining the Adequacy of Existing Ecological Arrangements

Yes No 1. Unsafe physical arrangements are eliminated or adjusted.

$\checkmark$ Objects or other structures that obstruct supervision are removed.

$\checkmark$ Barricades are used to limit access to areas that are not easily observed or that are off-limits to students.

Yes No 2. The density of students (numbers and space/distance) is reduced as much as possible.
$\checkmark$ All entrances and exits to a given area are utilized.
$\checkmark$ The age spread of students (balance of younger students with older ones) is increased as density increases to more fully utilize a given area.
$\checkmark$ Space/distance between groups/lines/classes are adequate $\left(10^{\prime}-15^{\prime}\right)$.

Yes No 3. The travel distance and wait time is reduced as much as possible?
$\checkmark$ Entrances and exits to a given area reduce travel distance.
$\checkmark$ The density of students is decreased as travel distance increases (e.g., staggered start times).
$\checkmark$ Wait time is short.

Yes No 4. Clear and stable signals are developed for behavioral expectations.

$\checkmark$ Physical signals for expected positioning of students (e.g., indicators where to line up).

$\checkmark$ Visual signals for expected behaviors (e.g., exit/entrance signs, posters depicting expected behaviors for a given area).

$\checkmark$ Auditory signals for expected behaviors (e.g., bells).

supervision and natural surveillance) can often be made on the school grounds. School grounds problems relate to the overall site plan. Although each site plan will be unique, the following are examples of the four most common problems. First, campus borders often are poorly defined. Even when fencing is used, sometimes it is obscured by foliage that shields the campus from natural surveillance. Second, undifferentiated campus areas (e.g., a hidden corner of the playground) present opportunities for informal gathering areas that are out of sight from supervision. These areas not only may be used for prohibited activities, but also may increase the incidence of problem behavior and victimization. Third, building layout and design often will produce isolated spots (e.g., end of the hallway) where students will gravitate and either commit prohibited activities or expose themselves to victimization. Finally, bus loading areas often are in direct conflict with traffic flow or may create conflict and congestion with 
FIGURE 2. Checklist for Determining the Adequacy of Existing Common Area Routes and Practices

Yes No 1. Are the behavioral expectations for each area of the school established?

$\checkmark$ There is consensus among staff/community on behavioral expectations.

$\checkmark$ Behavioral expectations are stated objectively.

$\checkmark$ Behavioral expectations are reasonable and limited in number.

Yes No 2. Is there an implementation plan to insure staff, students, and parents understand the behavioral expectations?

$\checkmark$ Behavioral expectations are written down.

$\checkmark$ Teaching plans for the behavioral expectations are developed

$\checkmark 180$ day implementation plan is established to insure that students understand and can perform the common area routines.

$\checkmark$ Staff understand their responsibility in insuring students and parents understand behavioral expectations.

Yes No 3. Is there adequate supervision?

$\checkmark$ Supervisors are trained.

$\checkmark$ Ratio of supervisors to students is adequate to promote positive social behavior.

$\checkmark$ There are established patterns of supervision.

$\checkmark$ Natural supervision is utilized (e.g., natural flow of parents, staff, etc., are used to promote positive student behavior).

$\checkmark$ Students are reinforced for exhibiting appropriate behavior.

Yes No 4. Are there effective reactive strategies in place to address minor prob. lem behavior?

$\checkmark$ Reactive strategies are reasonable, decisive (limited warnings), and provide students an opportunity to try again.

$\checkmark$ Reactive strategies reduce opportunities for students to manipulate or engage staff.

$\checkmark$ Strategies are designed to reduce the need for record keeping and communication.

$\checkmark$ Continuum of structures is in place to address chronic minor problem behavior.

$\checkmark$ Efficient record keeping and communication system is established to monitor chronic minor problem behavior.

Yes No 5. Is there a continuum of structures in place to address serious or challenging problem behavior?

$\checkmark$ Behaviors warranting office referral are delineated.

$\checkmark$ Efficient record keeping and communication system is established to monitor serious or challenging problem behavior.

$\checkmark$ Progressive levels of discipline that are focused on increasing levels of support for the student and staff. 
automobile parking areas. These zones also can be in direct conflict with the flow of students leaving the school grounds or entering for extra-curricular activities. Congestion created by traffic and student flow may provide an occasion for undesirable interactions between students.

\section{Improving Scheduling and Use of Space}

One of the most effective strategies for promoting positive social behaviors centers around improving the scheduling and use of space. For instance, it takes longer to get groups through the lunch line because of congestion. The congestion may provide occasions for more undesirable interactions between students. For example, one class may be passing through a doorway to exit the cafeteria while another class may be entering the cafeteria at the same time. Separating the cafeteria entrance and exit by space, or staggering the start and end of the lunch period can help define movement in and out of the area. Although there are no set rules for scheduling and using space, the following guidelines are recommended: (a) reduce the density of students by using all entrances and exits to a given area, increasing the space between groups/lines/classes, and increasing the age spread of students as the density of students increases; (b) insure that wait time is kept at a minimum; (c) reduce travel time and distance as much as possible; (d) use physical signs to control movement such as clearly marked transition zones that indicate movement from a less controlled to a more controlled space or to indicate behavioral expectations for the common areas of the school; and (e) insure that the sequence of events in the common areas are designed to facilitate the type of behavioral momentum desired (e.g., going to recess before lunch rather than going to lunch before recess results in students being better prepared for instruction).

\section{ESTABLISHING COMMON AREA ROUTINES}

The second major area examined for common areas in a school are the routines. Many school staff presume that students know the common area routines. We have found that these routines need to be systematically designed and taught. Based on the needs assessment, the building team identifies common area routines that promote positive social behavior and minimize problem behavior. The process of establishing effective common area routines includes: (a) identifying specific routines; (b) task analyzing the routines; (c) teaching and maintaining routines; and (d) responding to problem behavior. 


\section{Identifying the Routines}

Determining what school staff want to accomplish is the first step in establishing effective routines for the common areas of the school. The critical step is to identify the purpose of a given common area and then create a routine to achieve it. Routines for the common areas of the school typically evolve around three areas: (a) transitions; (b) administrative procedures; and (c) setting/activity requirements. Figure 3 presents some examples of routines that fall under each of these areas.

\section{Task Analysis of the Routines}

A task analysis of the routines for the common areas is used to specify, in a precise manner, the behavior required by students in the common areas. These behaviors should be discrete, sequential, and observable. Before writing up the task analyses for the common area routines, committee members should look at information gained from the needs assessment as well as try the common area routines a few times themselves. Committee members should become aware of different ways the common area routines can be done. Think about the needs of the staff and students, then select the behaviors that work best for each. Note that the level of detail in the task analysis depends on the kinds of problems that have been identified, the age of the students, and the size of the group. Figure 4 presents an example of a problem area identified in the needs assessment and the associated revised routine.

\section{Teaching and Maintaining Routines}

Teaching common area routines is much the same as teaching an academic concept or classroom routine. The more time spent teaching stu-

FIGURE 3. Routines for Common Areas of the School

\begin{tabular}{|c|c|c|}
\hline Transitions & Administrative & Selting/Activity \\
\hline $\begin{array}{l}\text { - Arrival } \\
\text { - Dismissal } \\
\text { - Hallways } \\
\text { - Bicycles } \\
\text { - Lining up }\end{array}$ & $\begin{array}{l}\text { - Fire drill } \\
\text { - Office communication } \\
\text { - Procedures if sent to office } \\
\text { for misbehavior }\end{array}$ & $\begin{array}{l}\text { - Cafeteria } \\
\text { - Recess (indoor and } \\
\text { outdoor) } \\
\text { - Restroom } \\
\text { - Safety Patrol } \\
\text { - Extracurricular } \\
\text { - Assemblies } \\
\text { - Bus }\end{array}$ \\
\hline
\end{tabular}


dents the common area routines the better the students will do. Typically, teachers develop a lesson plan to teach a skill that involves explanations, modeling, practice, correction procedures, feedback, and review (Walker, Colvin, \& Ramsey, 1995). Figure 5 outlines the major teaching elements included in a teaching or lesson plan for common area routines. The teaching elements parallel those used to teach an academic lesson, and require a well-developed lesson plan.

After teaching plans have been developed for each of the common areas of the school, instructional planning is the next step in establishing common area routines. This plan sequences which routines are taught on the first day of school, the second day of school, etc. Instructional planning includes: (a) prioritizing the routines with regard to how critical they are in maintaining a proactive positive school climate; and (b) developing a calendar plan for school staff to follow.

Identifying the desired behaviors in the common areas and teaching them does not guarantee that the students will demonstrate them throughout the year. There are no short cuts to effective and efficient common area routines. School staff must not only actively plan and teach students the common area routines, they must develop a 180-day maintenance plan to insure that students will continue to follow the common area routines. A 180-day maintenance plan includes three phases. In the first phase, students are taught the routines with high levels of supervision. This supervi-

FIGURE 4. Task Analysis of Routine for Students Coming in from Recess

\section{Problem Area dentified in Needs Assessment}

When the students come back from recess they rush to the classroom door, talk loudly, and many of the students are pushing and hitting each other. Teachers find it takes several minutes to get the students settled down in the classroom before they can start teaching.

\section{Task Analysis of Routine for Students Coming in from Recess}

The teacher meets the class at the door and signals to the students to line up.

Students form a single line with space between each student (no touching).

Students stay in their space for a brief second.

The teacher signals the students to enter the school.

The students enter the school walking quietly.

Students enter the classroom and go to their desk or assigned area.

Teacher gives students feedback on the extent to which they met the expectations.

Students begin work on assigned activity. 
FIGURE 5. Elements in a Lesson Plan for Teaching Common Area Routines

\begin{tabular}{|c|c|}
\hline Teaching Element & Description \\
\hline 1. Objectives & $\begin{array}{l}\text { A statement that articulates to students what they will } \\
\text { be able to do at the end of the lesson. }\end{array}$ \\
\hline 2. Rationale & $\begin{array}{l}\text { A statement that clearly explains to students the } \\
\text { importance of learning a skill, including personal } \\
\text { benefits and relevance. }\end{array}$ \\
\hline $\begin{array}{l}\text { 3. Modeling and Concept } \\
\text { Teaching }\end{array}$ & $\begin{array}{l}\text { Techniques utilizing a clear, explicit, and appropriate } \\
\text { range of examples and non-examples through multiple } \\
\text { demonstrations. Shows students what the behaviors } \\
\text { look like. }\end{array}$ \\
\hline 4. Role Playing & A procedure to provide practice through simulation. \\
\hline 5. Rehearsal & $\begin{array}{l}\text { Verbal or nonverbal procedure to provide practice } \\
\text { under controlled conditions. }\end{array}$ \\
\hline 6. Practice & $\begin{array}{l}\text { Guided and independent activities to minimize errors } \\
\text { and build learning. Gives students a chance to } \\
\text { demonstrate their understanding of the common area } \\
\text { routine. }\end{array}$ \\
\hline 7. Coaching & $\begin{array}{l}\text { A process to provide immediate and specific feedback } \\
\text { on the students' performance. }\end{array}$ \\
\hline 8. Feedback & $\begin{array}{l}\text { Descriptive information regarding students' correct and } \\
\text { incorrect performance of the routine. }\end{array}$ \\
\hline
\end{tabular}

sion must continue through the first two to three weeks of school, and should include high rates of social reinforcement and corrective feedback if necessary. The second phase involves conducting periodic reviews during the first two months of the school session (e.g., systematic review every Monday) with reduced levels of supervision. "Booster sessions" are conducted throughout the remainder of the year in the third phase (e.g., as needed and after holidays).

\section{Responding to Problem Behavior}

Teaching common area routines at the beginning of the year, and actively working to maintain them encourages appropriate behavior. However, students occasionally will exhibit problem behavior in spite of this proactive strategy. Thus, it is important for the committee to develop effective strategies for both minor and challenging problem behaviors. Although it is beyond the scope of this paper to fully describe a potential continuum of 
strategies for these behaviors, some factors should be considered when developing such strategies.

The basic response to problem behavior should be corrective in nature. That is, staff should respond to the student in a constructive and positive manner so that the problem behavior is identified and the students are directed to follow the routine. Overall, school staff respond to problem behavior quickly and directly. This implies that supervision needs to be active. Effectively implementing a continuum of responses to problem behavior in the common areas of the school begins with insuring that school staff are aware of what is going on at all times. Staff must be able to supervise one group of students while monitoring the rest. The ratio of supervisors to students must be adequate to promote positive social behavior. It is extremely difficult for staff who are supervising a common area of the school to be aware of what is going on if the ratio of staff to students is low. Establishing patterns of supervision enables staff to provide a more complete and balanced coverage of the common areas. Staff also need to be clear on behaviors warranting office referrals and which behaviors they should manage themselves. Staff will need to be given systematic training in the supervision of common areas and in implementing constructive responses to problem behavior.

Although schools should emphasize positive procedures, aversive interventions are a necessary part of a continuum of responses to problem behavior. It is important to note, however, that schools (and society) tend to rely on aversive interventions far too much. Nevertheless, aversive interventions help to deter problem behavior. Unfortunately, many of the typical aversive interventions used by schools (e.g., detention) are illdesigned, and may promote problem behavior rather than deter it. Aversive interventions should be designed to insure that they achieve their intended effect. The major issues to consider include: (a) insure that the aversive intervention is developed on the basis of its effect on students and not on the basis of its effect on school staff; (b) delineate and actively teach students what behaviors warrant the use of the aversive interventions; and (c) develop an informed-consent process such as a parent manual and/or individual communication structures.

\section{Implementing and Maintaining Ecological Arrangements and Common Area Routines}

A six-step review, revision, adoption, and evaluation process is used to implement and maintain the ecological arrangements and routines for the common areas of the school. The first step involves the development of a draft proposal. The draft proposal should contain a description of the 
current ecological arrangements and common area routines and a description of the revised arrangements and routines, including a discussion of the rationale for the changes (pros and cons).

In the second step, the draft proposal is presented to all staff for discussion. The committee should explain the process that the staff will use to review, revise, and adopt the ecological arrangements and common area routines. Staff should be given copies of the draft proposal a few days prior to the formal presentation of the proposal. This will allow staff adequate time to fully assess the implications of the revised ecological arrangements and common area routines, and to provide useful feedback and recommendations. In addition, it is important that the committee spend time explaining the development phase, especially a discussion of the design considerations and rationale that were used to develop the ecological arrangements and common area routines. Staff members will understand more fully the proposed ecological arrangements and common area routines if they are aware of those things that were considered in their development.

In the third step, the proposal is revised based on staff feedback and recommendations. Some ecological arrangements and common area routines may require major revisions, while others will be approved quickly. Quite often this is dependent upon the culture of the school and the process used for other school-wide matters. The review, revision, and adoption meetings should have an established agenda that is followed. This will enable the committee to move through the entire process in a timely manner. The second and third steps are repeated until consensus is achieved.

The fourth step involves presenting the final proposal to all staff for approval, including a staff development plan to insure the implementation of the ecological arrangements and common area routines. Staff development actually begins with the review, revision, and adoption process. Staff will begin to develop a common knowledge base as they consider, discuss, and finally adopt the ecological arrangements and common area routines. This process will provide them with an understanding of the design considerations, rationale, and fundamental changes in the ecological arrangements and common area routines. After this point, the committee should arrange the necessary staff development activities that will insure the successful implementation of the ecological arrangements and common area routines.

Fifth, a conceptually sound and properly implemented supervision system for school staff is a vital component of the effective implementation of the ecological arrangements and common area routines. Regardless of 
how well the ecological arrangements and common area routines have been designed, they are only as effective as the people who implement them. In other words, effective personnel insure effective ecological arrangements and common area routines.

The final step is evaluation. Four key points are critical to the evaluation of the ecological arrangements and common area routines. First, evaluation must be based on a variety of formal and informal information. Second, the evaluation information should be compared to baseline information collected during the needs assessment and subsequent evaluation data. Third, the evaluation findings must be shared with the entire school staff. Finally, the ecological arrangements and common area routines should be adjusted based on the results of the evaluation.

\section{CASE STUDY AND PRELIMINARY FINDINGS}

We will present some preliminary findings to illustrate the effects that establishing effective ecological arrangements and common area routines has on the social behavior of students. The findings are based on work conducted in a number of large elementary schools $(n=700)$ serving a low socioeconomic neighborhood (over $80 \%$ of the students receive free or reduced lunch). A typical recess lunch period will be used to illustrate the effects of effective ecological arrangements on the social behavior of students. Office referral data collected over a two-week period (a software package was used to track office referral data) in the school indicated high rates of problem behavior during the lunch recess period. Approximately 35 office referrals per week were made during the lunch recess. Close inspection of the office referrals indicated that a majority of them were made in response to students' behavior immediately prior to entering the school rather than during the lunch recess period itself. Observations revealed that students were required to line up two minutes prior to their teachers picking them up to return to the classroom. The wait time was reduced to 30 seconds. This resulted in a $98 \%$ reduction in office referrals during the lunch recess period.

Two typical common area routines will be used to illustrate the effects of well constructed routines on the social behaviors of students. Two primary dependent measures were used to assess the effects of well-constructed common area routines: (a) social behavior (positive and disruptive behavior during the breakfast and before school settings); and (b) disciplinary actions for the common areas of the school. (Optimal ecological arrangements were established prior to the implementation of the common area routines.) Figures 6 and 7 present the percentage of intervals scored as positive behavior 
FIGURE 6. Percentage of Intervals Scored as Positive Behavior

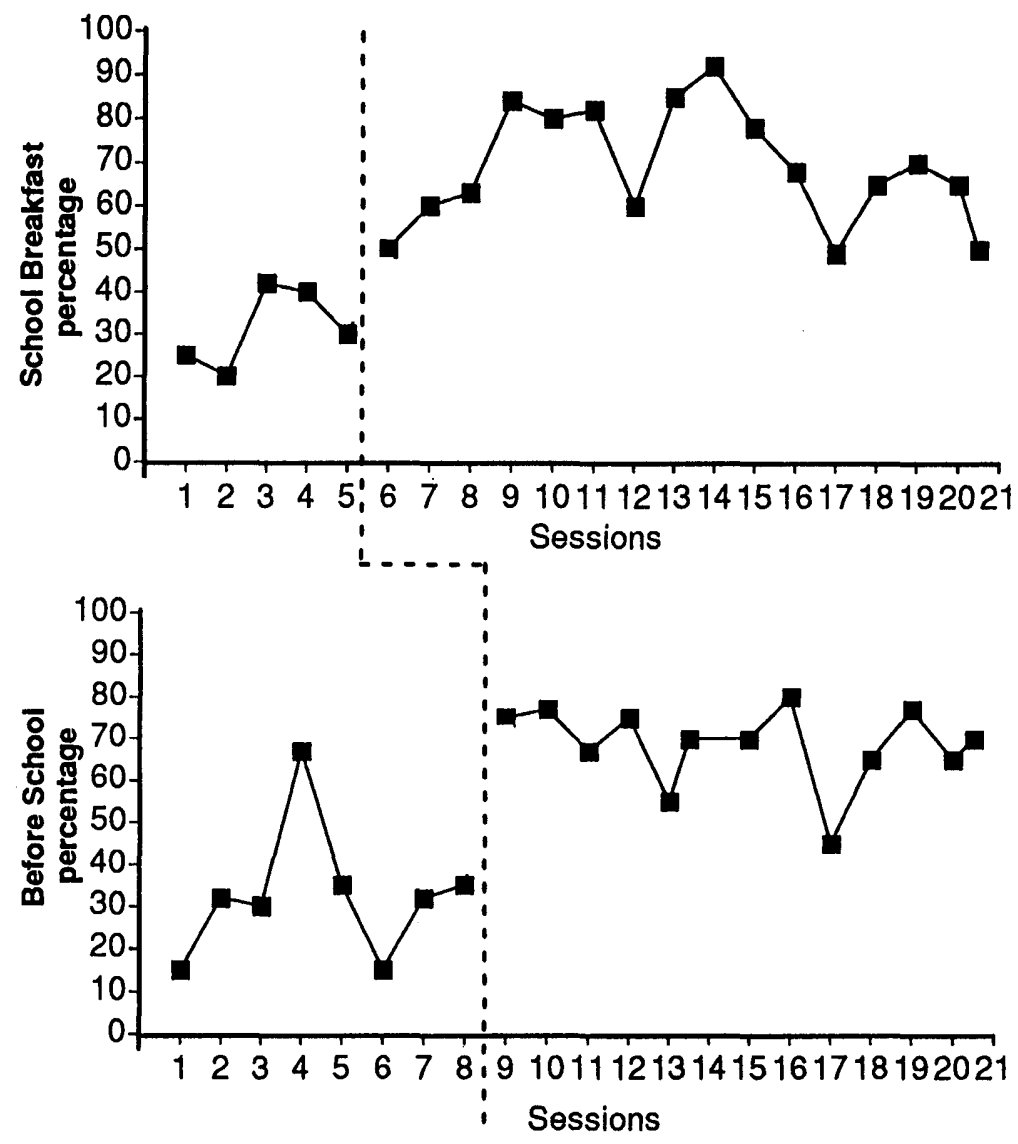

and disruptive behavior in the school breakfast and before school settings, respectively. The rates of positive behavior increased in both of these settings following the implementation of the school-wide program (see Figure 6). In contrast, the rates of disruptive behavior decreased in both the school breakfast and before school settings following the implementation of the school-wide program (see Figure 7).

The average number of referrals per day to the office for disciplinary action during baseline conditions for the common areas of the school was approximately 5 (range 1 to 11). Following the implementation of the school-wide program, the average number of referrals to the office for 
FIGURE 7. Percentage of Intervals Scored as Disruptive Behavior

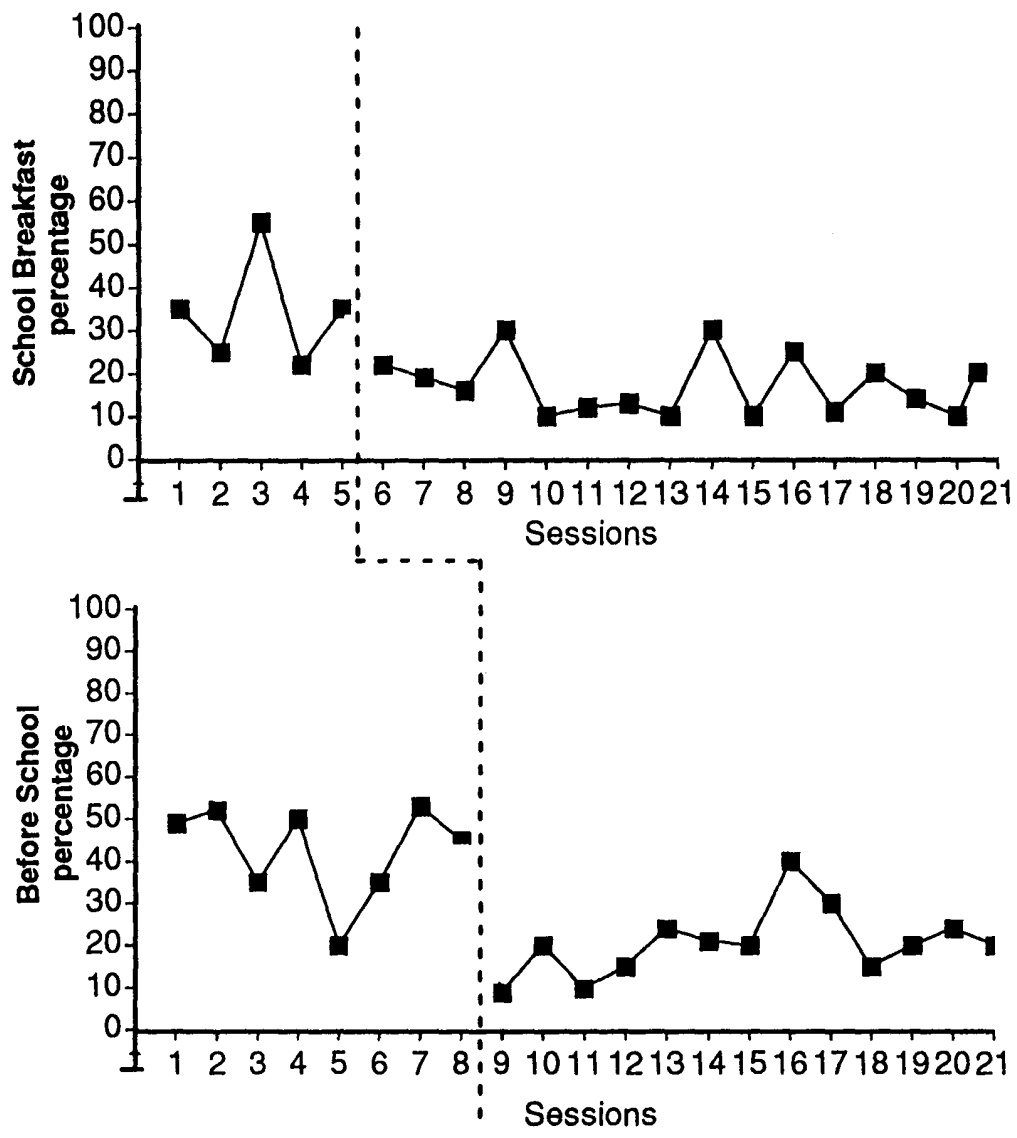

disciplinary action decreased. The average number for the common areas of the school was approximately 1 (range 0 to 5).

\section{CONCLUSION}

Developing supportive school environments are critical to the success of all students including those with SED. This is especially critical because the management of problem behavior or the "lack of discipline" has been identified by the public as the most persistent and possibly the most troublesome issue facing schools (Center \& McKittrick, 1987; Cotton, 1990; Elam, Rose, \& Gallup, 1992; Jones, 1993). Increasingly, public 
school personnel are facing problem behavior that occurs more frequently and that significantly affects staff and student safety (Greenbaum \& Turner, 1989). Further, significant shifts in patterns of poverty and in family characteristics occurring in the demographic makeup of the United States will add to this problem. In short, our nation's schools must reconceptualize their fundamental approach to addressing the more complex patterns of social behavior that confront them. A basic part of this reorientation will center on reconceptualizing school-wide discipline practices. The purpose of this paper was to describe an approach designed to achieve effective ecological arrangements and routines in the common areas of the school.

Clear and salutary changes in social behavior occurred for students when the ecological arrangements and common area routines were introduced. The rates of positive child social behavior increased and the rates of negative child social behavior decreased. These rates maintained throughout the experimental condition. The introduction of the program also reduced the rates of negative adult social behavior and increased the rates of positive adult social behavior. These findings suggest that ecological arrangements and routines in the common areas of the schools play a role in the social behavior of students.

Converging evidence for the effectiveness of achieving effective ecological arrangements and common area routines comes from previous work conducted on the disciplinary actions taken with junior high school students (Colvin, Sugai, \& Kameenui, 1994). In this study, a similar comprehensive instructional approach to school-wide and classroom management was implemented at a junior high school. The findings indicated that the approach significantly reduced disciplinary actions. For example, there was a $50 \%$ decrease in office referrals for problem behavior. Notable decreases also were observed in office conferences, suspensions, detentions, and parent meetings.

Finally, the process of designing a supportive school staff also benefits the entire staff. The design and implementation process requires that staff work together and develop consensus on a wide range of discipline issues. As a result of this process, staff report that the working environment of the school is more supportive and collegial. In addition, staff report that they are more satisfied with their jobs and that they are more confident in their ability to work with children with challenging behavior.

\section{REFERENCES}

Center, D. B., \& McKittrick, S. (1987). Disciplinary removal of special education students. Focus on Exceptional Children, 20(2), 1-9.

Colvin, G., Sugai, G., \& Kameenui, E. (1994). Reconceptualizing school-wide discipline. Education and Treatment of Children, 16, 361-381. 
Cotton, K. (1990). School improvement series, close-up \#9: School wide and classroom discipline. Portland, OR: Northwest Regional Educational Laboratory.

Edgar, E., \& Levine, P. (1987). Special education students in transition: Washington State data 1976-1986. Seattle: University of Washington, Experimental Education Unit.

Elam, S. E., Rose, L. C., \& Gallup, A. M. (1992). The 24th annual Gallup/Phi Delta Kappa poll of the public's attitudes toward public schools, Kappan, 74(1), 41-53.

Gilbert, P. (1993). Defense and safety: Their function in social behaviour and psychopathology. British Journal of Clinical Psychology, 32, 131-153.

Greenbaum, S., \& Turner, B. (Eds.) (1989). Safe schools overview: NSSC resource paper. Malibu, CA: U.S. Department of Justice, U.S. Department of Education and Pepperdine University.

Jones, V. (1993). Assessing your classroom and school-wide student management plan. Beyond Behavior, 4(3), 9-12.

Kauffman, J. M., Cullinan, D., \& Epstein, M. H. (1987). Characteristics of students placed in special programs for the seriously emotionally disturbed. $B e$ havioral Disorders, 12, 175-184.

Morrison, G. M., Furlong, M. J., \& Morrison, R. L. (1994). School violence to school safety: Reframing the issue for school psychologists. School Psychology Review, 23, 236-256.

Neel, R., Meadows, N., Levine, P., \& Edgar, E. (1988). What happens after special education: A statewide follow-up study of secondary students who have behavioral disorders. Behavioral Disorders, 13(3), 209-216.

Walker, H., Colvin, G., \& Ramsey, E. (1995). Antisocial behavior in school: Strategies and best practices. Pacific Grove, CA: Brooks/Cole. 